\title{
Após as Audiências de Custódia: necessidade de apoio a mães em liberdade provisória ou prisão domiciliar ${ }^{1}$
}

Vilma Diuana

Luciana Simas ${ }^{3}$

Thaís Nascimento 4

Bernard Larouzé5

Alexandra Sánchez ${ }^{6}$

\section{Resumo}

Obstáculos de acesso ao Bolsa Família são marcantes para gestantes e mães com filhos de até 12 anos ou deficientes, as quais se encontram em liberdade provisória ou prisão domiciliar. Este artigo problematiza o perfil sociodemográfico dessas muIheres, que passaram pelas audiências de custódia (RJ). Foram realizadas 63 entrevistas, demonstrando que famílias que não recebem Bolsa Família têm renda média per capita duas vezes e meia inferior à das que o recebem e $70 \%$ possuem prévio encarceramento. É fundamental a cooperação entre sistema de justiça e serviços de proteção social, para uma atenção integral a essas mulheres e suas famílias.

Palavras-chave

Mulheres; Assistência social; Bolsa família; Audiência de custódia; Prisões.

After the Pretrial Detention Hearings: necessity of support towards mothers on temporary release or house arrest

\begin{abstract}
Obstacles to accessing the Bolsa Familia are significant for pregnant women and mothers with children up to 12 years old or disabled, who are on temporary release or under house arrest. This article problematizes these women's sociodemographic profiles after being released from the pretrial detention hearings in Rio de Janeiro. The analysis of the 63 interviews demonstrated that families who do not receive this benefit have an average income per capita two and a half times lower than those that receive it, and that $70 \%$ were previously incarcerated. Cooperation between the justice system and social protection services is essential for comprehensive care for these women and their families.
\end{abstract}

Keywords

Women; Social assistance; Family grant; Pretrial detention hearing; Prisons.

Artigo recebido: fevereiro de 2021

Artigo aprovado: abril de 2021 


\section{Introdução}

Nos últimos anos, diversos estudos apontaram as consequências do encarceramento sobre a vida e a saúde das mulheres privadas de liberdade e de seus filhos (DIUANA et al., 2016, 2017; LEAL et al, 2016; VENTURA et al, 2015; ITTC, 2017). No mesmo sentido, movimentos sociais de mulheres e de direitos humanos enfatizam os problemas decorrentes das desigualdades sociais e de gênero que afetam as mães nessa situação e suas famílias. Essas iniciativas têm contribuído para o desenvolvimento de políticas públicas de assistência social e de saúde voltadas para essa população (DEPEN, 2016) e para a produção de medidas jurídicas visando seu desencarceramento, com proteção social (BRASIL, 2011; BRASIL, 2014).

Mudanças ocasionadas pelo Marco Legal da Primeira Infância (BRASIL, 2016) e pelo Habeas Corpus coletivo concedido pelo Supremo Tribunal Federal (STF, 2018) para converter a prisão preventiva de mães com filhos até 12 anos ou com deficiência em prisão domiciliar produziram reflexos no âmbito jurídico e na assistência social (SIMAS et al, 2019). Neste mesmo ano, o Conselho Nacional de Política Criminal e Penitenciária - CNPCP e o Conselho Nacional de Assistência Social - CNAS (2018) publicaram a Resolução Conjunta n01, pela qual determinam que a rede socioassistencial deve atuar de forma articulada com o Sistema Penitenciário para o adequado atendimento das famílias de mulheres com filhos até 12 anos incompletos ou com deficiência, grávidas e lactantes que tiveram decretada prisão em flagrante delito, bem como mulheres egressas do Sistema Penitenciário, como forma de ampliar o acesso aos serviços, programas, projetos e benefícios sociais. Observa-se que as políticas sociais dirigidas às gestantes e mães começam a avançar formalmente no sentido de garantir seus direitos e apontar a responsabilidade da sociedade e do Estado na promoção de condições e recursos que contribuam para prevenir situações de vulnerabilidade, garantindo seus direitos, entre outros, o direito à convivência familiar e o acesso a serviços públicos de qualidade. 
Também nesta perspectiva de garantia de direitos, desde 2015, toda pessoa presa em flagrante deve ser apresentada a um juiz, em até 24 horas após sua prisão, para ser ouvida em uma audiência de custódia (CNJ, 2015), quando será decidido se permanecerá presa ou se responderá ao processo em prisão domiciliar ou em liberdade. Trata-se de procedimento construído com base em determinações de tratados internacionais (BRASIL, 1992), que atinge inclusive centenas de mulheres diariamente no país. A audiência de custódia é um direito de todas as pessoas, por uma questão de equidade, para se verificar as reais condições do aprisionamento, sua legalidade e consequências sociais. Essa iniciativa preenche uma importante lacuna processual, especialmente diante do grave cenário do aumento preocupante do encarceramento em massa e de superlotação das prisões, que faz do Brasil a terceira maior população carcerária do mundo, com destaque para o crescimento especialmente acelerado do aprisionamento feminino (DEPEN, 2018).

Entre setembro de 2017 e setembro de 2019, somente no estado do RJ, foram apresentadas 1.283 mulheres às audiências de custódia, sendo que $498(41,4 \%)$ ficaram presas preventivamente e $36(2,8 \%)$ foram mantidas em prisão domiciliar (DPRJ, 2020). Outras 668 mulheres (55,1\% de casos com informação) receberam liberdade provisória ou tiveram sua prisão relaxada por ter sido considerada ilegal. Embora este percentual de liberdades seja superior ao do total de homens e mulheres no mesmo período (30\%), outro estudo, realizado também com dados do RJ (SIMAS, 2018), mostrou a dificuldade das mulheres em cumprir as medidas cautelares impostas e se beneficiarem de ações de saúde no âmbito do SUS ou de programas sociais.

Neste artigo, objetivamos conhecer o perfil sociodemográfico e familiar das mulheres liberadas durante as audiências de custódia e identificar os obstáculos que dificultam seu ingresso no Sistema Único de Assistência Social (SUAS), em especial no acesso ao Bolsa Família. Apresentaremos um recorte dos resultados da pesquisa 
interdisciplinar "Inovar para cuidar, cuidar para transformar: saúde materna e assistência para presas provisórias", que analisa as particularidades e principais vulnerabilidades sociais de gestantes e muIheres com filhos de até 12 anos ou deficientes, as quais, no estado do RJ, respondiam a processo criminal em liberdade provisória ou prisão domiciliar. Tais resultados extrapolam o âmbito local e podem refletir barreiras estruturais de acesso aos serviços de proteção social por parte de mulheres que foram encarceradas.

A escolha do Bolsa Família justifica-se por se tratar do principal programa de transferência de renda do governo federal, cuja regulamentação prevê o combate à fome e à pobreza, por meio de um benefício financeiro conjugado a direitos sociais básicos, como saúde e educação (SILVA, 2007). Este benefício que, em 90\% dos casos é recebido diretamente pelas mães ou mulheres das famílias, atinge atualmente cerca de um quinto da população brasileira, ou seja, mais de $40 \mathrm{mi}$ Ihões de pessoas (FGVSocial, 2020).

\section{Metodologia}

Foram realizadas entrevistas individuais com gestantes, mães ou responsáveis por crianças $\leq 12$ anos ou portadoras de deficiência, que saíram das audiências de custódia, em dias úteis e iriam responder ao processo criminal em liberdade provisória ou prisão domiciliar. Estes critérios foram estabelecidos porque são utilizados para definir as beneficiárias do Habeas Corpus coletivo n 143.641 (STF, 2018). Foram excluídas as mulheres que tiveram a prisão preventiva decretada ou que recusaram o convite para participar da pesquisa.

A coleta de dados foi realizada, em sua maioria, no período inicialmente previsto de 13 de maio a 26 de junho de 2019, na Central de Audiências de Custódia (CEAC) de Benfica no município do Rio de Janeiro, órgão responsável pela apreciação das prisões em flagrante na capital e região metropolitana (Baixada Fluminense), região dos Lagos e Serrana, concentrando $80 \%$ das audiências re- 
alizadas no estado (TJRJ, 2017). O trabalho de campo teve que ser interrompido em razão de obras no espaço da CEAC e mudanças na Coordenação das Audiências de Custódia, sendo finalizado em setembro e outubro do mesmo ano.

As entrevistas, individuais, ocorreram após as audiências, em local reservado, sem a presença de agentes estatais. Apenas em dois dias não puderam ser realizadas por imposição da escolta da SEAP (Secretaria de Administração Penitenciária) /RJ. Foi utilizado questionário estruturado para coleta de informações sociodemográficas, composição da família e do domicílio, renda e benefícios sociais. Para a análise dos dados foi utilizado o software Epi Info. Os resultados foram organizados em tabelas e apresentados ao longo do texto.

Os conceitos de pobreza e extrema pobreza foram definidos segundo os critérios utilizados pelo Programa Bolsa Família, que considera famílias "extremamente pobres" aquelas com renda per capita mensal de até $\mathrm{R} \$$ 89,00, independentemente de sua composição; e famílias “pobres" com renda per capita entre $\mathrm{R} \$ 89,01$ e $\mathrm{R} \$ 178,00$, desde que possuam gestantes, ou nutrizes, ou crianças e adolescentes entre zero e quinze anos em sua composição.

O estudo foi autorizado pelo Tribunal de Justiça do Estado do Rio de Janeiro e aprovado pelo Comitê de Ética em Pesquisa da Escola Nacional de Saúde Pública/Fiocruz (Parecer: 3.132.010 de 05/02/2019).

\section{Resultados e Discussão}

Foram entrevistadas 63 mulheres, incluindo 58 mães com filhos < 12 anos; 2 grávidas do $1^{\circ}$ filho, 1 guardiã de sobrinho de 27 anos, portador de deficiência e 2 avós que detinham a guarda de netos $\leq$ de 12 anos. Como mostra a Tabela 1, nosso estudo mostrou que essas muIheres, em sua grande maioria pretas ou pardas (76,3\%), tinham pouca escolaridade, majoritariamente com ensino fundamental incompleto $(53,2 \%)$, sendo que uma delas nunca estudou. Eram jovens, predominantemente na faixa etária entre 18 e 29 anos (49,9\%). De acordo com 
dados do Instituto Brasileiro de Geografia e Estatística (IBGE, 2010), as jovens representam $18,74 \%$ da população feminina da cidade do Rio de Janeiro e, dentre essas jovens, 46,9\% são negras. Apesar do público atendido da Central de Custódia em Benfica não se restringir ao município do Rio de Janeiro, há uma evidente sobrerrepresentação da população jovem e negra na dinâmica das audiências de custódia, exigindo um olhar atento tanto para os aspectos da seletividade penal (BARATTA, 2002), como para as ações de inserção social e sanitária desta população. Do total das entrevistadas, $1 / 3$ (20/63) tinha história de algum encarceramento anterior. $O$ fato da maioria das mulheres liberadas (43/63) nunca ter passado pelo sistema de justiça criminal, sugere, nessa população, que não ter sido presa anteriormente constitui fator que favorece a liberação.

Tabela 1. Características sociodemográficas de gestantes ou mães/avós responsáveis por crianças $\leq 12$ anos ou deficientes, liberadas após as audiências de custódia (Central de Audiências de Custódia, RJ).

\begin{tabular}{|c|c|c|}
\hline & $N^{0}$ & $\%$ \\
\hline \multicolumn{3}{|l|}{ Faixa etária $(n=62)$} \\
\hline 18 a 24 anos & 15 & 24,2 \\
\hline 25 a 29 anos & 16 & 25,8 \\
\hline 30 a 44 anos & 27 & 43,6 \\
\hline 45 a 60 anos & 4 & 6,4 \\
\hline \multicolumn{3}{|l|}{ Cor da pele $(n=59)$} \\
\hline Preta & 14 & 23,7 \\
\hline Parda & 31 & 52,6 \\
\hline Branca & 14 & 23,7 \\
\hline \multicolumn{3}{|l|}{ Escolaridade $(\mathrm{n}=62)$} \\
\hline Nunca estudou & 1 & 1,6 \\
\hline 1 a 4 anos de estudo & 3 & 4,8 \\
\hline 5 a 7 anos & 30 & 48,4 \\
\hline 8 anos ou mais & 28 & 45,1 \\
\hline \multicolumn{3}{|c|}{ Encarceramento anterior $(n=63)$} \\
\hline Não & 43 & 68,2 \\
\hline Sim & 20 & 31,8 \\
\hline \multicolumn{3}{|c|}{ Local de moradia $(n=57)$} \\
\hline Comunidade & 25 & 43,9 \\
\hline Em situação de rua & 3 & 5,3 \\
\hline Outro & 29 & 50,8 \\
\hline
\end{tabular}




\begin{tabular}{|l|c|c|}
\hline Situação conjugal $(n=58)$ & & \\
\hline Mora com companheiro & 25 & 43,1 \\
\hline Mora sem companheiro & 33 & 56,9 \\
\hline Chefe de família $(n=63)$ & & \\
\hline A própria & 27 & 42,9 \\
\hline Outros & 36 & 57,1 \\
\hline Número de fillhos * $(n=61)$ & & \\
\hline 1 filho & 13 & 21,3 \\
\hline 2 a 3 filhos & 39 & 63,9 \\
\hline 4 filhos ou mais & 9 & 14,8 \\
\hline
\end{tabular}

\section{Fonte: Elaboração própria.}

*Não incluídas 2 gestantes sem filhos

No que diz respeito às condições de moradia, 25 mulheres entrevistadas residiam em comunidades, em sua maioria carentes de serviços públicos essenciais, e 3 encontravam-se em situação de rua, condição que, como mostra estudo de Mendes, Ronzani \& Paiva (2019), envolve processos de vulnerabilização anteriores à ida para as ruas e limitação de acesso aos direitos e bens imposta pela desigualdade social.

As famílias possuíam configurações diversas. Tomando-se o espaço da casa como referência, algumas se enquadravam num padrão de convivência unicamente entre pais e filhos ou mãe e filhos, enquanto outras incluíam alguns parentes, como avós paternos e maternos, tios, tias, primos e sobrinhos. A grande maioria das mães $(78,7 \%)$ tinha 2 filhos ou mais, os quais, no momento de sua detenção, ficaram, majoritariamente, aos cuidados das muIheres das famílias, em especial as avós maternas (29,8\%), tias maternas $(10,5 \%)$ e de amigas (22,8\%). Os pais ficaram responsáveis pelos filhos em apenas $5,3 \%$ dos casos.

Mais da metade das mulheres entrevistadas relatou não morar com companheiro(a) (56,9\%) e 42,9\% eram chefes de família. Neste cenário, deve ser considerado o grave impacto das decisões judiciais sobre a vida destas famílias, mesmo que algumas mulheres possam, eventualmente, contar com a solidariedade familiar ou da vizinhança no cuidado de seus filhos. 
Como evidenciado na Tabela 2, quase 2/3 das mães relataram trabaIhar, essencialmente em atividades relacionadas à prestação de serviços em tempo parcial e sem vínculos trabalhistas, como manicures, faxineiras ou ambulantes. Embora 67,2\% (47/61) das mulheres entrevistadas tivessem carteira de trabalho, somente uma possuía o documento assinado por seu empregador, revelando o contexto de desemprego e precarização das relações de trabalho em que vivem. Ainda assim, $60 \%$ das muIheres contribuem com $>50 \%$ da renda familiar e 38,3\% com sua quase totalidade. Se, por um lado, esses dados apontam para as situações de vulnerabilidade social e econômica em que se encontram estas mulheres, também indicam, com clareza, a importância delas para a manutenção de suas famílias e as consequências que seu eventual aprisionamento ou a imposição de medidas cautelares pode representar para a vida de seus filhos e outros familiares que, muitas vezes, dependem dela.

Tabela 2. Características socioeconômicas de gestantes ou mães/avós responsáveis por crianças $\leq 12$ anos ou deficientes liberadas por ocasião das audiências (Central de Audiências de Custódia, RJ).

\begin{tabular}{|c|c|c|}
\hline & \\
\hline & $N^{\circ}$ & $\%$ \\
\hline \multicolumn{3}{|l|}{ Trabalha atualmente $(n=63)$} \\
\hline Sim, com carteira assinada & 1 & 1,6 \\
\hline Sim, sem carteira assinada & 36 & 57,1 \\
\hline Não trabalha & 26 & 41,3 \\
\hline \multicolumn{3}{|c|}{ Contribuição da mãe na renda familiar $(n=60)$} \\
\hline 0 a $24 \%$ & 20 & 33,3 \\
\hline 25 a $49 \%$ & 4 & 7,7 \\
\hline 50 a $74 \%$ & 13 & 21,7 \\
\hline 75 a $100 \%$ & 23 & 38,3 \\
\hline \multicolumn{3}{|l|}{ Recebe Bolsa Familial* $(n=62)$} \\
\hline $\operatorname{Sim} *$ & 27 & 43,5 \\
\hline Não & 35 & 56,5 \\
\hline
\end{tabular}

\section{Fonte: Elaboração própria}

*Além de Bolsa Família, 1 mãe recebia auxílio financeiro da Agência da ONU para Refugiados (ACNUR); e outra recebia Benefício de Prestação Continuada (BPC). 
Apesar da evidência das implicações decorrentes desses e outros contextos de vulnerabilidade na vida dessas mulheres e de suas famílias, bem como da necessidade de ações de assistência social que Ihes assegurem o acesso aos direitos e lhes possibilitem a superação destas situações, mais da metade (56,5\%) das mulheres entrevistadas não recebia nenhum tipo de benefício social. Como o mostra a tabela 3, entre as 60 famílias sobre as quais a informação da renda foi obtida, 28 (46,7\%) tinha renda per capita mensal entre $\mathrm{R} \$ 185,00 \mathrm{e}$ $\mathrm{R} \$ 400,00$; enquanto 21 (35\%) possuíam renda per capita $\leq \mathrm{R} \$ 185,00$ ou $\leq R \$ 89,00$, podendo ser classificadas, respectivamente, como pobres $(n=11)$ ou extremamente pobres $(n=10)$, de acordo com critérios do Programa Bolsa Família, no ano de 2019. Deve ser ressaltado que a metade das famílias vivendo em situação de pobreza ou extrema pobreza não recebiam o Bolsa família. É importante assinalar que contar com esse benefício social permitiu que 3 das famílias em extrema pobreza passassem à situação de pobreza; e 2 famílias pobres saíssem da situação de pobreza.

Tabela 3. Distribuição segundo a renda per capita familiar e a inclusão no Programa Bolsa Família de gestantes ou mães/avós responsáveis por crianças $\leq 12$ anos ou deficientes liberadas por ocasião das audiências de custódia (Central de Audiência de Custódia, RJ).

\begin{tabular}{|c|c|c|c|c|}
\hline \multirow[b]{2}{*}{$\begin{array}{l}\text { Situação } \\
\text { econômica }\end{array}$} & \multirow[b]{2}{*}{$\begin{array}{c}\text { Renda per } \\
\text { capita (Reais)* }\end{array}$} & \multirow[b]{2}{*}{$\begin{array}{l}\text { Total } \\
\mathrm{N}^{\circ}(\%)\end{array}$} & \multicolumn{2}{|c|}{ Recebia Bolsa Família } \\
\hline & & & $\underset{\mathrm{N}^{\circ}(\%)}{\operatorname{sim}}$ & $\begin{array}{c}\text { Não } \\
\left.\text { NN }^{\circ} \%\right)\end{array}$ \\
\hline \multirow{2}{*}{$\begin{array}{l}\text { Extrema } \\
\text { pobreza }\end{array}$} & $\begin{array}{l}\text { Nenhuma } \\
\text { renda }\end{array}$ & $4(6,7)$ & $3(75,0)$ & $1(25,0)$ \\
\hline & $1-89$ & $6(10,0)$ & $2(33,3)$ & $4(66,6)$ \\
\hline \multirow{4}{*}{ Pobreza } & $90-185$ & $11(18,3)$ & $6(54,5)$ & $5(54,5)$ \\
\hline & $186-399$ & $28(46,7)$ & $11(39,3)$ & $17(60,7)$ \\
\hline & $400-1.000$ & $8(13,3)$ & $2(25,0)$ & $6(75,0)$ \\
\hline & $>1.000$ & $3(5,0)$ & - & $3(100,0)$ \\
\hline \multicolumn{2}{|l|}{ Total } & $60(100)$ & $24(40,0)$ & $36(60,0)$ \\
\hline
\end{tabular}

\section{Fonte: Elaboração própria}

*3 famílias sem informação sobre renda (1 recebia BF e 2 não recebiam) 
Nossos resultados mostram que as famílias que não recebiam o Bolsa Família, apesar de atenderem ao critério de renda para obtê-lo, tinham renda média per capita duas vezes e meia inferior à das famílias que recebem este benefício (renda per capita $\mathrm{R} \$ 92,70$ vs. R\$ 231,96). Isto indica que a falta de recursos monetários pode constituir um mecanismo que realimenta a exclusão, dificultando o acesso ao benefício e contribuindo para a manutenção do círculo vicioso da pobreza. Inclusive, o cumprimento regular das determinações judiciais constitui uma dificuldade adicional para as mulheres em liberdade provisória ou prisão domiciliar, particularmente, no custo de deslocamento para o controle periódico pelo Judiciário. Muitas delas têm até mesmo dificuldades financeiras para retornarem a suas casas por ocasião da saída da audiência de custódia.

Outro importante aspecto que está associado ao não recebimento do referido benefício é a história de passagem anterior pela prisão. Observou-se que $70 \%$ das famílias que têm renda per capita dentro dos critérios exigidos para a concessão do Bolsa Família e não estão inseridas no programa, são famílias de mulheres com história de prévio encarceramento. Além de dificultar a inserção na família e no mercado de trabalho, o fato de ter antecedentes criminais também parece representar um forte obstáculo à utilização de serviços de instituições públicas e à obtenção dos benefícios sociais a que fazem jus. Deste modo, a prisão vulnerabiliza ainda mais essas mulheres e suas famílias, agravando situações de opressão e desigualdade. Reduz seu acesso aos meios necessários à superação das situações e contextos de vulnerabilidade que enfrentam no seu cotidiano, intensificando o circuito de exclusão, no qual são relançadas diante do novo encarceramento.

Como observado nas entrevistas, cabe ainda sinalizar que, na passagem anterior pelo sistema de justiça criminal, a maioria destas muIheres não foi abordada nem ouvida, como recomendado pelo DEPEN (2016), por profissionais da assistência social ou da saúde para avaliar os contextos de vulnerabilidade e desigualdade que marcam suas vi- 
das e de suas famílias, para providenciar as medidas de apoio necessárias. Ao contrário, a ausência de articulação da justiça com outras políticas públicas, com aplicação exclusiva de medidas cautelares e punitivas, faz recair sobre elas a responsabilidade pela não superação das situações de desigualdade e exclusão que marcam suas trajetórias e, ainda mais, as agrava pelas limitações adicionais que lhes são impostas por medidas cautelares ou restrições da prisão domiciliar.

\section{Considerações finais}

Até onde temos conhecimento, este é o primeiro estudo empírico a sobre a situação social e econômica de mulheres liberadas nas audiências de custódia em liberdade provisória ou prisão domiciliar no Brasil. Nossa análise demonstra que gestantes e mulheres com filhos até 12 anos ou deficientes, em prisão domiciliar ou liberdade provisória, de modo geral, encontram-se em situação de extrema vulnerabilidade social, com dificuldades de acesso a trabalho e renda, bem como a serviços de assistência social e de saúde que possam contribuir para a redução das desigualdades sociais, proporcionando-lhes acesso aos meios necessários à superação das situações que enfrentam no seu cotidiano. Ressalta também que o aprisionamento marginaliza ainda mais essas mulheres, presumidamente inocentes, e suas famílias, de tal maneira que as medidas que lhes são impostas, muitas vezes ultrapassem elas próprias, impactando fortemente na vida de seus filhos.

Nesta conjuntura, as audiências de custódia em todo o país podem constituir uma oportunidade para se conhecer as situações de risco e vulnerabilidade em que se encontram estas mulheres e suas famílias, buscando promover a inclusão daquelas que não acessam os programas e benefícios da assistência social, nem os serviços de saúde disponíveis nos territórios.

Nosso estudo evidencia a necessidade de ampliar a cooperação entre o Sistema de Justiça e os serviços de proteção social e de saúde, a fım de oferecer uma atenção integral atenta às questões relacionadas 
aos processos de vulnerabilização atuantes na vida destas mulheres e suas famílias, inclusive no próprio contexto jurídico-penal. Trata-se de criar, juntamente com os serviços sociais locais, uma rede que possibilite um acompanhamento, ao mesmo tempo judicial e social, extenso à saúde, com pleno acesso aos benefícios e direitos sociais.

Deste modo, os encaminhamentos para as redes de assistência social e de saúde, que são um direito, podem contribuir para a redução da reincidência e das iniquidades que afetam a vida das mulheres detidas e encaminhadas às audiências de custódia, sem os quais dificilmente conseguirão enfrentar as difıculdades que vivenciam em seu cotidiano.

Antes mesmo do julgamento e, inclusive, na perspectiva de uma eventual condenação, uma cooperação intersetorial, desde a audiência de custódia, permitiria desenvolver mecanismos de articulação entre os sistemas de justiça, de saúde e assistência social, com implantação de rotinas para assegurar os direitos das mulheres autuadas e suas famílias. Tal integração entre as políticas criminal, de assistência social e de saúde pode beneficiar a custodiada e seus filhos, uma vez que muitas delas são as únicas responsáveis pelo sustento da família. Também, em uma perspectiva ampla e sistêmica, beneficia a coletividade como um todo, contribuindo para o enfrentamento da questão social, para a redução do encarceramento em massa, de diversos tipos de violência dele decorrentes e, finalmente, para que a prisão como um local de morte social - possa ser substituída por alternativas intersetoriais de inclusão social.

\section{Referências}

BARATTA, Alessandro. Criminologia crítica e crítica do direito penal: introdução à sociologia do direito penal. 3. ed. Rio de Janeiro: Revan/ICC, 2002.

BRASIL. Secretaria Nacional de Assistência Social. Atenção às famílias das mulheres grávidas. Lactantes e com filhas/os até 12 anos incompletos ou com deficiência privadas de liberdade. Brasília, 2018. Disponível em: http:// www.mds.gov.br/webarquivos/publicacao/crianca_feliz/Documento\%20 mulheres\%20encarceradas\%20final.pdf. Acesso em: 22 fev. 2021. 
BRASIL. Portaria Interministerial $n^{\circ} 210$, de 16 de janeiro de 2014. Institui a Política Nacional de Atenção às Mulheres em Situação de Privação de Liberdade e Egressas do Sistema Prisional, e dá outras providências. Diário Ofıcial [da] República Federativa do Brasil, Poder Executivo, Brasília, DF, 2014.

BRASIL. Lei $n^{\circ} 12.403$, de 4 de maio de 2011. Altera dispositivos do Decreto-Lei n 3.689, de 3 de outubro de 1941 - Código de Processo Penal, relativos à prisão processual, fiança, liberdade provisória, demais medidas cautelares, e dá outras providências. Brasília: Diário Oficial da União, 2011.

BRASIL. Decreto $n^{\circ}$ 678, de 6 de novembro de 1992. Promulga a Convenção Americana sobre Direitos Humanos (Pacto de São José da Costa Rica), de 22 de novembro de 1969. Brasília: Diário Oficial da União, 1992.

BRASIL. Lei $n^{\circ} 13.257$, de 08 de março de 2016. Dispõe sobre as políticas públicas para a primeira infância e altera a Lei n 8.069 , de 13 de julho de 1990 (Estatuto da Criança e do Adolescente), o Decreto-Lei n 3.689, de 3 de outubro de 1941 (Código de Processo Penal), a Consolidação das Leis do Trabalho (CLT), aprovada pelo Decreto-Lei ${ }^{\circ} 5.452$, de $1^{\circ}$ de maio de 1943 , a Lei $n^{\circ} 11.770$, de 9 de setembro de 2008, e a Lei ${ }^{\circ} 12.662$, de 5 de junho de 2012. Brasília: Diário Oficial da União, 2016. Disponível em: http://www. planalto.gov.br/ccivil_03/_ato2015-2018/2016/lei/l13257.htm. Acesso em 11 de nov. 2020.

BRASIL. Ministério da Cidadania. Bolsa Família. S/d. Disponível em: https:// www.gov.br/cidadania/pt-br/acesso-a-informacao/carta-de-servicos/desenvolvimento-social/bolsa-familia-1

CNJ - CONSELHO NACIONAL DE JUSTIÇA. Resolução 213, de 15 de dezembro de 2015. Dispõe sobre a apresentação de toda pessoa presa à autoridade judicial no prazo de 24 horas. Disponível em: https://www.cnj.jus.br/ wp-content/uploads/2019/04/resoluo-n213-15-12-2015-presidncia.pdf Acesso em 11 de nov. 2020.

CNPCP - CONSELHO NACIONAL DE POLÍTICA CRIMINAL E PENITENCIÁRIA; CNAS - CONSELHO NACIONAL DE ASSISTÊNCIA SOCIAL. Resolução Conjunta $n^{\circ} 1$, de 7 de novembro de 2018. Qualifica o atendimento socioassistencial às famílias de pessoas encarceradas e egressas do Sistema Penitenciário no Sistema Único de Assistência Social - SUAS. Brasília: Diário Oficial da União, 2018. Disponivel em https://www.in.gov.br/materia/-/asset_publisher/KujrwOTZC2Mb/content/id/49740886/do1-2018-11-12-resolucao-conjunta-n-1-de-7-de-novembro-de-2018-49740585. Acesso em: 22 fev. 2021. 
268 Vilma Diuana, Luciana Simas, Thaís Nascimento, Bernard Larouzé e Alexandra Sánchez

DPRJ - DEFENSORIA PÚBLICA DO ESTADO DO RIO DE JANEIRO. Perfil dos entrevistados pela Defensoria Pública do Rio de Janeiro nas audiências de custódia entre setembro de 2017 e setembro de 2019, 2020. Disponível em: https://www.defensoria.rj.def.br/uploads/arquivos/0b6d8d161c1b41739e7fc20ccaOcle39.pdf. Acesso em: 22 fev. 2021.

DEPARTAMENTO PENITENCIÁRIO NACIONAL (DEPEN). Ministério da Justiça. Levantamento Nacional de Informações Penitenciárias - INFOPEN MuIheres. 2. ed. Brasília: Ministério da Justiça e Segurança Pública, 2018. Disponível em: https://www.conectas.org/wp/wp-content/uploads/2018/05/ infopenmulheres_arte_07-03-18.pdf Acesso em: 11 maio 2019.

DEPARTAMENTO PENITENCIÁRIO NACIONAL (DEPEN). Ministério da Justiça. Diretrizes para a Convivência Mãe-Filho/a no Sistema Prisional. Coordenação e redação: Renata Barreto Preturlan e Rosângela Peixoto Santa Rita. Documento resultado do workshop "Convivência Mãe Filho /a no Sistema Prisional", realizado em Brasília-DF nos dias 1 e 2 de março de 2016. Disponível em: https://carceraria.org.br/wp-content/uploads/2018/01/formacao-diretrizes-convivencia-mae-filho-1.pdf Acesso em: fevereiro de 2021.

DIUANA, V. et al. Direitos reprodutivos das mulheres no sistema penitenciário: tensões e desafios na transformação da realidade. Ciência \& Saúde Coletiva, v.21, n.7, p. 2041-2050, 2016.

DIUANA, V. et al. Mulheres nas prisões brasileiras: tensões entre a ordem disciplinar punitiva e as prescrições da maternidade. Physis: Revista de Saúde Coletiva, v.27, n.3, p. 727-747, 2017.

FGVSOCIAL. FGV Social comenta os cortes no Bolsa Família e o aumento da extrema pobreza no Brasil. 2020. Disponível em: https://cps.fgv.br/destaques/fgv-social-comenta-os-cortes-no-bolsa-familia-e-o-aumento-da-extrema-pobreza-no-brasil. Acesso em: 06 fev. 2021.

INSTITUTO TERRA, TRABALHO E CIDADANIA (ITTC). Mulheres sem prisão: desafios e potencialidades para a redução do encarceramento de mulheres. São Paulo: ITTC, 2017. Disponível em: <http://ittc.org.br/wp-content/uploads/2017/03/relatorio_final_online.pdf>. Acesso em: 06 fev. 2018.

IBCE - INSTITUTO BRASILEIRO DE GEOGRAFIA E ESTATÍSTICA. Censo Demográfico, 2010. Disponível em: https://sidra.ibge.gov.br/Tabela/3175. Acesso em: 06 fev. 2021. 
MENDES, Kíssila Teixeira; RONZANI, Telmo Mota; PAIVA, Fernando Santana de. População em situação de rua, vulnerabilidades e drogas: uma revisão sistemática. Psicologia \& Sociedade, v.31, e169056, 2019. Disponível em https://dx.doi.org/10.1590/1807-0310/2019v31169056. Acesso em: 06 fev. 2021.

SILVA, Maria Ozanira da Silva e. O Bolsa Família: problematizando questões centrais na política de transferência de renda no Brasil. Ciência \& Saúde Coletiva, v.12, n.6, p.1429, 2007.

SIMAS, Luciana et al. Saúde materna e infantil nas prisões: contribuições para o Habeas Corpus coletivo 143.641. In: INSTITUTO ALANA. Pela Liberdade: a história do Habeas Corpus coletivo para mães \& crianças. São Paulo: Instituto Alana, 2019, p. 48-55. Disponivel em https://prioridadeabsoluta.org.br/ wp-content/uploads/2019/05/pela_liberdade.pdf Acesso em: 06 fev. 2021.

SIMAS, Luciana. Direito à maternidade e (des)encarceramento feminino no Brasil: perspectivas éticas e jurídicas da punição criminal. Tese (Doutorado). Programa de Pós-graduação em Bioética, Ética Aplica e Saúde Coletiva, Universidade Federal do Rio de Janeiro. Rio de Janeiro: 2018.

STF - SUPREMO TRIBUNAL FEDERAL. Segunda Turma. HC 143.641/SP. Pacientes: Todas as mulheres submetidas à prisão cautelar no sistema penitenciário nacional, que ostentem a condição de gestantes, de puérperas ou de mães com crianças com até 12 anos de idade sob sua responsabilidade, e das próprias crianças. Coatores: Juízes e juízas das varas criminais estaduais, Tribunais dos Estados e do Distrito Federal e Territórios, juízes e juízas federais com competência criminal, Tribunais Regionais Federais e Superior Tribunal de Justiça. Relator: Min. Ricardo Lewandowski. Brasília, DF, 20 de fevereiro de 2018. Diário Oficial da União. Brasília, 01 mar. 2018. Disponível em: http:// www.stf.jus.br/arquivo/cms/noticiaNoticiaStf/anexo/HC143641final3pdfVoto.pdf. Acesso em 11 de nov. 2020.

TJRJ - TRIBUNAL DE JUSTIÇA DO ESTADO DO RIO DE JANEIRO. Tribunal de Justiça amplia audiências de custódia para todo o estado. 2017. Disponível em http://www.tjrj.jus.br/noticias/noticia/-/visualizar-conteudo/5111210/5201290. Acesso em 11 de nov. 2020.

VENTURA, M. et al. Maternidade atrás das grades: em busca da cidadania e da saúde. Um estudo sobre a legislação brasileira. Cadernos de Saúde Pública, v.31, n.3, p. 607-619, 2015. 


\section{Notas}

1 Os autores agradecem a autorização do Tribunal de Justiça do estado do Rio de Janeiro, bem como o apoio prestado pela Defensoria Pública do estado do Rio de Janeiro. Agradecem, ainda, a colaboração prestada por Vanessa Figueiredo Lima e Isabela Arezzo na coleta de dados, como integrantes do Grupo de Pesquisa "Saúde nas Prisões"/Fiocruz. A pesquisa obteve financiamento do Programa Inova FIOCRUZ- Ideias Inovadoras, 2018.

2 Doutora em Ciências da Saúde/UERJ. Pesquisadora do Grupo de Pesquisa Saúde nas Prisões - ENSP/FIOCRUZ. Brasil. https://orcid.org/0000-0002-7373-3446. E-mail: vilmadiuana@gmail.com

3 Doutora em Bioética, Ética Aplicada e Saúde Coletiva/UFRJ. Pesquisadora do Grupo de Pesquisa Saúde nas Prisões - ENSP/FIOCRUZ. Brasil https://orcid. org/0000-0003-2494-8747. E-mail: lucianasimas06@gmail.com.

4 Graduanda em Ciências Sociais/UfRJ. Bolsista do Programa de Iniciação Científica ENSP/FIOCRUZ. Brasil. https://orcid.org/0000-0002-3046-6245. E-mail: thaais.carvalhoo@hotmail.com.br.

5 Doutor em Medicina, Pesquisador Emérito INSERM, France. Pesquisador do Grupo de Pesquisa Saúde nas Prisões - ENSP/FIOCRUZ. Brasil. https://orcid.org/00000001-9906-6293. E-mail: larouzebernard@gmail.com

6 Doutora em Saúde Pública, ENSP/Fiocruz. Coordenadora do Grupo de Pesquisa Saúde nas Prisões - ENSP/FIOCRUZ. Brasil. https://orcid.org/0000-0001-56171173. E-mail: alexandra.sanchez@ensp.fiocruz.br 